\title{
Generalized joint hypermobility among school-aged children in Majmaah region, Saudi Arabia
}

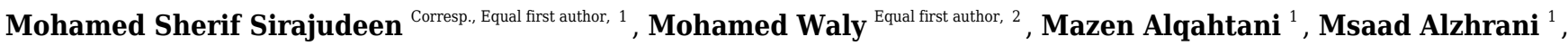 \\ Fahad Aldhafiri ${ }^{3}$, Hariraja Muthusamy ${ }^{1}$, Radhakrishnan Unnikrishnan ${ }^{1}$, Rashmi Saibannavar ${ }^{1}$, Wafa Alrubaia $^{1}$, \\ Gopal Nambi ${ }^{4}$ \\ 1 Department of Physical Therapy and Health Rehabilitation, College of Applied Medical Sciences, Majmaah University, Majmaah 11952, Saudi Arabia \\ 2 Department of Medical Equipment Technology, College of Applied Medical Sciences, Majmaah University, Majmaah 11952, Saudi Arabia \\ 3 Department of Public Health and Health Informatics, College of Applied Medical Sciences, Majmaah University, Majmaah 11952, Saudi Arabia \\ 4 Department of Physical Therapy and Health Rehabilitation, College of Applied Medical Sciences, Prince Sattam Bin Abdul Aziz University, Alkharj, Saudi \\ Arabia
}

Corresponding Author: Mohamed Sherif Sirajudeen

Email address: m.sirajudeen@mu.edu.sa

Generalized joint hypermobility $(\mathrm{GJH})$ is common among schoolchildren and usually benign. However, it may progressively lead to joint pain and developmental delay. Identifying GJH in school-aged children would facilitate the monitoring of early changes and planning for early rehabilitative intervention. Epidemiological studies addressing the prevalence of $\mathrm{GJH}$ among children in the Gulf region and Arab ethnicity are lacking. Hence, we aimed to determine the prevalence, pattern, and factors associated with $\mathrm{GJH}$ among school-aged children in the Majmaah region, Saudi Arabia. Male and female school-aged children 8-14 years of age from the Majmaah region of Saudi Arabia participated in this cross-sectional study. Beighton score was used to assess GJH. Personal characteristics such as age, height, weight, body mass index, and handedness were also collected. Descriptive statistics were obtained for personal characteristics, the point prevalence of hypermobility, frequency of Beighton score distribution, and prevalence of $\mathrm{GJ} \mathrm{H}$. The associations between specific factors and the presence of $\mathrm{GJH}$ were analyzed using chi-square and Mann-whitney tests. Using the Beighton score cutoff $\geq 4$ and $\geq 6,15.2 \%$ and $7.6 \%$ of the school children in our study were diagnosed with $\mathrm{GJH}$ respectively. The prevalence of $\mathrm{GJH}$ was higher among females $(16.8 \%)$ than among males (13.4\%), but the difference was not statistically significant. The elbow joints (17.2\%) were the most common hypermobile joints and the trunk $(0.7 \%)$ was the least involved. The children with $\mathrm{GJH}$ were younger and had lesser $\mathrm{BMI}$ compared to children without $\mathrm{GJH}(\mathrm{P}<0.05)$. The prevalence reported in this study among school-aged children was comparable with those reported worldwide. 
1

ORIGINAL RESEARCH

2 Generalized joint hypermobility among school-aged children in 3 Majmaah region, Saudi Arabia

5 Mohamed Sherif Sirajudeen ${ }^{1}$, Mohamed Waly ${ }^{2,}$, Mazen Alqahtani ${ }^{1}$, Msaad Alzhrani ${ }^{1}$, Fahad Aldhafiri ${ }^{3}$, Hariraja

6 Muthusamy $^{1}$, Radhakrishnan Unnikrishnan ${ }^{1}$, Rashmi Saibannavar ${ }^{1}$, Wafa Alrubaia ${ }^{1}$, Gopal Nambi ${ }^{4}$

$7 \quad{ }^{1}$ Department of Physical Therapy and Health Rehabilitation, College of Applied Medical Sciences, Majmaah

8 University, Majmaah 11952, Saudi Arabia; ${ }^{2}$ Department of Medical Equipment Technology, College of Applied

9 Medical Sciences, Majmaah University, Majmaah 11952, Saudi Arabia; ${ }^{3}$ Department of Public Health and Health Informatics, College of Applied Medical Sciences, Majmaah University, Majmaah 11952, Saudi Arabia;

${ }^{4}$ Department of Physical Therapy and Health Rehabilitation, College of Applied Medical Sciences, Prince Sattam

Bin Abdul Aziz University, Alkharj, Saudi Arabia

Correspondence: Dr. Mohamed Sherif Sirajudeen

Assistant Professor

Department of Physical Therapy and Health Rehabilitation

17 College of Applied Medical Sciences

Majmaah University, Majmaah 11952, Saudi Arabia

E-mail: m.sirajudeen@mu.edu.sa 
22 Abstract

23 Generalized joint hypermobility $(\mathrm{GJH})$ is common among schoolchildren and usually benign.

24 However, it may progressively lead to joint pain and developmental delay. Identifying GJH in

25 school-aged children would facilitate the monitoring of early changes and planning for early

26 rehabilitative intervention. Epidemiological studies addressing the prevalence of GJH among

27 children in the Gulf region and Arab ethnicity are lacking. Hence, we aimed to determine the

28 prevalence, pattern, and factors associated with GJH among school-aged children in the Majmaah

29 region, Saudi Arabia. Male and female school-aged children 8-14 years of age from the Majmaah

30 region of Saudi Arabia participated in this cross-sectional study. Beighton score was used to assess

31 GJH. Personal characteristics such as age, height, weight, body mass index, and handedness were

32 also collected. Descriptive statistics were obtained for personal characteristics, the point

33 prevalence of hypermobility, frequency of Beighton score distribution, and prevalence of GJH.

34 The associations between specific factors and the presence of GJH were analyzed using chi-square

35 and Mann-whitney tests. Using the Beighton score cutoff $\geq 4$ and $\geq 6,15.2 \%$ and $7.6 \%$ of the school

36 children in our study were diagnosed with GJH respectively. The prevalence of GJH was higher

37 among females (16.8\%) than among males (13.4\%), but the difference was not statistically

38 significant. The elbow joints $(17.2 \%)$ were the most common hypermobile joints and the trunk

$39(0.7 \%)$ was the least involved. The children with GJH were younger and had lesser BMI compared

40 to children without GJH $(\mathrm{P}<0.05)$. The prevalence reported in this study among school-aged

41 children was comparable with those reported worldwide.

42 Keywords: Beighton score, Joint hypermobility, Ligamentous laxity, Prevalence, Children, Saudi 43 Arabia 


\section{Introduction}

An increase in mobility of one or more joints compared to the normal range is referred to as joint hypermobility (Romeo et al., 2016). Ligament laxity is the primary cause of joint hypermobility (Grahame, 2000). Ligament laxity and the resulting joint hypermobility are cardinal features of genetic disorders such as Marfan syndrome, Ehlers-Danlos syndrome, or osteogenesis imperfecta (Armon et al., 2012). However, in most cases, joint hypermobility is observed as a confined phenomenon referred to as generalized joint hypermobility (GJH). Rarely, in the absence of any genetic disorders, joint hypermobility is associated with features such as arthralgia, back pain, dislocation/subluxation, soft tissue rheumatic disorders, marfanoid habitus, skin abnormalities, eye signs, incompetence of the lower-limb vessel valves, or rectal hernia or prolapse and is termed joint hypermobility syndrome (Alsiri et al., 2020; Armon et al., 2012; Clinch et al., 2011; Palmer et al., 2014; Palmer et al., 2015).

The reported occurrence of GJH in children aged 6-15 years varies between $8.8 \%$ (Vougiouka et al., 2000) and 64.6\% (Lamari et al., 2005). The prevalence of GJH is high in girls and declines with age (Bird et al., 1978; Bulbena et al., 1992; Hudson et al., 1995; Larsson et al., 1987; Silman et al., 1987). In a study of Swedish school children, Jansson et al. reported that girls presented with marked joint hypermobility versus boys regardless of age. However, the presentation of joint laxity in boys decreases as age increases, whereas joint laxity peaks in girls at 15 years of age (Jansson et al., 2004). Earlier researchers demonstrated an influence of ethnic background on GJH; specifically, a high prevalence of GJH among Asian and African populations compared to the Western population (Beighton et al., 1973; Bird, 2005; Carter et al., 1964; Jessee et al., 1980). However, the prevalence of GJH in Arabic children is lacking in the literature (Sirajudeen, 2020). 
(Juul et al., 2007; Smits-Engelsman et al., 2011). Beighton's method includes the assessment of

70

71

72

73

74

hypermobility in nine joints (bilateral thumbs, bilateral little fingers, bilateral elbows, bilateral knees, and trunk). The score ranges from 0 to $9 ; 1$ point is awarded for the participant's ability to perform each component of the test (Beighton et al., 1973). All nine tests were easy to perform and provide quantitative data. Earlier prevalence studies adopted cutoffs ranging from $\geq 3$ to $\geq 6$ hypermobile joints for the diagnosis of GJH. The most frequent choice of cutoff score for GJH was $\geq 4$ (Clinch et al., 2011). International Consortium on the Ehlers Danlos syndromes (EDS) proposed cut-off score of $\geq 6$ for diagnosis of GJH for pre-pubertal children and adolescents (Malfait et al., 2017; Reuter et al., 2019). A recent systematic review on Measurement Properties of Clinical Assessment Methods for Classifying Generalized Joint Hypermobility also recommended a cut-off of minimum $\geq 6$ for diagnosis of GJH in children (Juul et al., 2017). Juul et al. and Smits-Engelsman et al. recommended the administration of standard protocols in children (Juul et al., 2007; Smits-Engelsman et al., 2011).

Prevalence studies related GJH cater vital data about the burden of this entity in each population reflected by number of individuals affected. This provide valuable input to plan the healthcare needs. GJH is common among schoolchildren and usually benign. However, it may lead to joint pain and developmental delay (Jaffe et al., 1988). Identifying GJH during the school years would facilitate the monitoring of early changes and planning for early rehabilitative intervention (Lamari et al., 2005). Epidemiological studies addressing the prevalence of GJH among children reflecting Arab ethnicity in the Gulf region are lacking (Sirajudeen, 2020). Hence, this study, the first of its kind in Saudi Arabia and the entire Gulf region, aimed to explore the prevalence of GJH and its associated factors in school-aged children in the Majmaah region. 


\section{Methods}

93

94

95

\section{Study design, setting, and participants}

Male and female school-aged children aged 8-14 years from the Majmaah region of Saudi Arabia participated in this cross-sectional study. Permission was obtained from the Information and Planning Authority for Education - Majmaah, under the Ministry of Education, Saudi Arabia. Majmaah region consists of 15 primary schools with 1755 children belonging to the $8-14$ age group. Out of the which, 3 schools were selected by cluster sampling method and all the 311 children were approached for the study. A letter describing the study design and seeking the cooperation of Headteachers of Schools was sent. The data were collected between October and December 2018 in their respective schools. Children with any apparent or reported disabilities such as cognitive, developmental, or bodily as per the medical data available in school were not included in this study (Romeo et al., 2016).

\section{Anthropometry measurements}

Data related to personal characteristics like age (years), sex, height (centimeters), and weight (kilograms) were collected. Height and weight were measured by the gold standard method (in bare feet; measured to the closest $1 \mathrm{~cm}$ and $100 \mathrm{~g}$, respectively). The body mass index (BMI) calculation was performed using a metric formula, weight (in kilograms) divided by height (in meters squared) and children were sorted as underweight (BMI < 18.5), ideal weight (BMI 18.524.9), overweight (BMI 25-29.9), or obese (BMI > 30) as per the recommended criteria (Gerver \& de Bruin, 2001). 


\section{Beighton score for screening $G J H$}

115 The screening criteria comprises five clinical tests; each was assigned 0 or 1 based on the subject's 116 ability to complete it. These test scores are summed at the end, and the totals range from 0 to 9.

117 1. Researcher passively performs thumb apposition to the flexor side of the forearm on the 118 right and left sides, and a score of 1 is awarded if the entire thumb touches the flexor side and Beighton maneuvers were performed by two physical therapists with 15 years of experience in the pediatric practice and research. The inter-rater reliability of the therapists was measured in 20 subjects and determined as 0.98 (Intraclass correlation). 
136

137

138

139

140

141

142

143

144

145

146 147 study.

\section{Sample size calculation}

We calculated sample size using the Sample Size Calculation for Estimating a Single Proportion method. Since this is the first study to investigate the prevalence of GJH in the entire Gulf region, we used the prevalence of 16\% reported among Egypt children (El-Garf et al., 1998). The required sample size was 207 with $95 \%$ confidence and 5\% absolute precision.

\section{Ethical consideration}

Approval was obtained from Majmaah University Ethical Committee (no. MUREC Oct21/COM-2018/6). Each child's parents were provided information about the study, after which they provided a written informed consent to permit their child to participate in the research. Moreover, assent was also obtained from the participating children before their enrollment in this

Statistical analysis

150 The data were recorded in a Microsoft Excel spreadsheet and analyzed using SPSS (version 17.0) 151 for Windows. Descriptive statistics were obtained for personal characteristics, the point prevalence 152 of hypermobility, and frequency of Beighton score distribution. The prevalence of GJH was 153 calculated by dividing the number of children diagnosed with GJH (Beighton cutoff score $\geq 4$ or $154 \geq 6$ ) by the total number of students who participated in the study. The data were tested for 155 normality and homogeneity of variance for deciding appropriate statistics. The chi-square statistic 156 was used to compute the association between binary variables and the presence/absence of GJH.

157 The Mann-whitney test was used to determine association between the continuous variables and 
158 the presence/absence of GJH. The level of probability of 5\% was used to indicate statistical 159 significance.

160

161

162

163

164

165

166

167

168

169

170

171

172

173

174

175

176

177

178

179

\section{Results}

Out of 311 children approached, eight were sick on the day of examination. A total of 303 children participated in this study. Their personal characteristics are presented in Table 1. Most of the participating children were female (53.1\%). The mean age of the children was 10.74 years and ranged from 8 to 14 years. Most of the children were underweight (53.1\%), whereas 34.7\%, 7.9\%, and $4.3 \%$ were normal weight, overweight, and obese, respectively. Most of the participants were right-handed $(95.7 \%)$.

The distribution of the total Beighton score of the participants is presented in Table 2. Most of the participants (75.6\%) did not exhibit hypermobility in any of the tested joints (Beighton score, $0)$. None of the participants in this present study demonstrated hypermobility in all tested sites. The occurrence of GJH as formulated by a Beighton cutoff score $\geq 4$ in the 303 participated primary school children was $15.2 \%$ (males, $13.4 \%$; and females, $16.8 \%$ ). When a more vigorous cutoff ( $\geq 6$ ) was used, the prevalence was $7.6 \%$ (males, $4.5 \%$; and females, $9.9 \%$ ).

Table 3 represents the distribution of the participants' joint hypermobility. The occurrence of hypermobility was high in the elbows $(17.2 \%)$, followed by the thumbs $(12.5 \%)$, little fingers $(12.5 \%)$, knees $(8.6 \%)$, and trunk $(0.7 \%)$. The proportion of males and females with hypermobility of left little finger (15.5\% in males vs. $8.1 \%$ in females), right little finger $(18.3 \%$ in males vs. $7.4 \%$ in females), left thumb (4.9\% in males vs. $19.2 \%$ in females) and right thumb (4.9\% in males vs. $18 \%$ in females) were statistically significant $(\mathrm{P}<0.05)$. Trunk hypermobility in males was 
180 181

unusual, as none of our 142 male subjects could place their palms flat on the ground with the knees in full extension.

The association between personal characteristics and GJH is summarized in Table 4. The prevalence of GJH was higher among females (16.8\%) than males (13.4\%), but this difference was not statistically significant. The children with GJH (Cut-off $\geq 4$ ) were younger compared to children without GJH. The difference in age was statistically significant $(\mathrm{P}<0.05)$ for the entire sample and marginally significant $(\mathrm{P}=0.05)$ in males but not in females. The BMI of children with GJH was lesser compared to children without GJH. The difference in BMI was statistically significant $(\mathrm{P}<0.05)$ for the entire sample (Cut-off $\geq 4)$ and in females (Cut-off $\geq 4$ and $\geq 6)$ but not in males. The children with GJH were similar to children without GJH with regard to hand dominance.

\section{Discussion}

This is the first study in the entire Gulf region, reflecting the Arab ethnicity, to report the prevalence of GJH among school children aged 8-14 years. In the present study, the prevalence of GJH was $15.2 \%$ with use of the cutoff score $\geq 4$ hypermobile joints from the 9-point Beighton scoring system. The prevalence reported in our study is comparable to those reported of children in Denmark (9.4\%), Egypt (16\%), and the United Kingdom (19.2\%) but lower than those reported of children in Iceland (27.7\%), Italy (35.4\%), and India (61.2\%) (Clinch et al., 2011; El-Garf et al., 1998; Gyldenkerne et al., 2007; Hasija et al., 2008; Leone et al., 2009; Qvindesland \& Jonsson,1999) . The difference in the prevalence of GJH reported in this study as compared to some other locations may be attributed to the ethnic influence. Earlier researchers also demonstrated an influence of ethnic background on GJH; specifically, a high prevalence of GJH among Asian and African populations compared to the Western population (Beighton et al., 1973; 
203 Bird, 2005; Carter et al., 1964; Jessee et al., 1980). The prevalence of GJH was higher among

204 females $(16.8 \%)$ than males $(13.4 \%)$, but this difference was not statistically significant $(\mathrm{P}<0.05)$.

205 This finding is consistent with the rates reported by El-Garf et al. of Egyptian children (males, 206 14.4\%; females, 18\%) (El-Garf et al., 1998). Gyldenkerne et al. reported a significantly higher 207 occurrence of GJH among female children (16.6\%) than among male children (3\%) in Denmark 208 (Gyldenkerne et al., 2007). None of the earlier studies reported a higher incidence of GJH in males 209 than in females (Clinch et al., 2011; El-Garf et al., 1998; Gyldenkerne et al., 2007; Hasija et al., 210 2008; Leone et al., 2009; Qvindesland \& Jonsson, 1999).

211 The female children in our study predominantly presented with hypermobility of the thumb 212 and elbow, whereas the male children were commonly presented with hypermobility at the fingers 213 and elbows. It was fascinating that our subjects showed considerably less hypermobility in the 214 lumbar spine. This may be described by the factuality that the most of the range of flexion of the 215 lumbar spine is a conjoint of extensibility of the hamstrings and actual vertebral flexion (Corben 216 et al., 2008); short hamstrings would be a factors that are associated with reduced lumbar flexion 217 in males (Gajdosik et al., 1994). A perceived reduction in flexion of the lumbar spine may have 218 been caused by tight hamstrings, which in turn could be a reason for the low occurrence of 219 hypermobility of the lumbar spine among the boys in the present study.

220 In our study, the rate of hypermobility decreased as age increased in male but not female 221 subjects. Studies of Egyptian and Swedish children reported an inverse age-related decrease in the 222 prevalence of GJH in both males and females (El-Garf et al., 1998; Jansson et al., 2004). The 223 degree of collagen cross-linking is related to joint hypermobility, which is believed to increase the 224 collagen's ability to attract and hold water and thereby increase joint mobility. As age increases, 225 body water decreases and cross-linking of collagen molecules increases, accounting for the 
226 decrease in joint hypermobility. Increased muscle fiber diameter is another factor that would

227 reduce joint mobility at an older age (Lamari et al., 2005; Smits-Engelsman et al., 2011). Beighton

228 et al. stated that joint laxity is at its maximum at birth and decreases quickly during childhood, less

229 quickly in adolescence, and more slowly during adulthood (Beighton et al., 1999).

230

In our study, the prevalence of GJH was positively associated with BMI in females but not

231

232

233

234

235

236

237

238

239

240

241

242

243

244

245

246

247

248

in males. The BMI of female children with GJH was lesser compared to those without GJH. Clinch

et al. also reported a positive association between GJH and BMI among females but not males.

But in their study, obese females were 2.7 times more likely to be hypermobile than underweight females (Clinch et al., 2011). In contrast, a previous study from India reported an association between hypermobility and moderate to severe malnutrition (Hasija et al., 2008). Using cut-off $\geq 6$, the prevalence of GJH was associated with BMI in females and not in males. No other associations were seen using cut-off $\geq 6$ to define GJH. A previous study in the United Kingdom using a Beighton score cutoff $\geq 6$ compared with $\geq 4$ to measure generalized joint laxity (GJL), reported stronger evidence of associations between physical activity and maternal education. The authors also suggested raising the cutoff from $\geq 4$ to $\geq 6$ to determine GJH (Clinch et al., 2011). We also recommend the use of criteria proposed by International Consortium on the EDS; Cut-off $\geq 6$ for prepubertal children and adolescents to define GJH in the future studies (Malfait et al., 2017). This will hopefully facilitate comparison between the results and reduces the ambiguity in the future.

\section{Study limitations}

One of the limitations of the present study is that the clinical symptoms studied by previous researchers were not assessed (El-Garf et al., 1998; Hasija et al., 2008; Leone et al., 2009; 
249 Qvindesland \& Jonsson,1999; Seçkin et al., 2005). Thus, the correlations between GJH and

250 clinical symptoms are unclear. Al-Rawi et al., who studied university students aged 20-24 years,

251 reported a correlation between joint hypermobility and symptoms/signs including joint complaints

252 and ligamentous sprains (Al-Rawi et al., 1985). Mikkelson and Qvindesland studied 12-year-old

253 children and reported that hypermobility was not associated with any kind of joint symptoms

254 (Grahame, 1999; Mikkelsson et al., 1996; Qvindesland \& Jonsson,1999). A further limitation of

255 the present study is that parental or sibling hypermobility, which could be an added risk factor for

256 hypermobility, was not assessed. Like the limitations encountered in any other observational

257 studies, we can neither rule out confounders and chance nor establish causal or temporal

258 relationships of the reported associations.

\section{Conclusion}

261

262

263

264

265

266

267

268

269

270

Using the Beighton score cutoff $\geq 4$ and $\geq 6,15.2 \%$ and $7.6 \%$ of the school children in our study were diagnosed with GJH respectively. The prevalence reported in this study among school-aged children was comparable with those reported worldwide. The elbow joints were the most common hypermobile joints and the trunk was the least involved. The children with GJH were younger and had lesser BMI compared to children without GJH.

\section{Acknowledgments}

The authors thank the Deanship of Scientific Research at Majmaah University for supporting this work (project no. 38/146). The authors also thank the Information and Planning Authority for 
271 Education - Majmaah, under the Ministry of Education, Saudi Arabia, for permitting this study.

272 Finally, the authors thank the school authorities, school children, and parents for their cooperation

273 and participation in this research.

274

275 Disclosure

276 The authors report no conflicts of interest in this work.

277

278

279

\section{References}

280

281

282

283

284

285

286

287

288

289

290

291

292

293

294

295

296

297

Al-Rawi ZS, Al-Aszawi AJ, Al-Chalabi T. 1985. Joint mobility among university students in Iraq. Br J Rheumatol 24:326-331.

Alsiri N, Cramp M, Barnett S, Palmer S. 2020. Gait biomechanics in joint hypermobility syndrome: a spatiotemporal, kinematic and kinetic analysis. Musculoskeletal Care : 1- 14.

Armon K, Bale P. 2012. Identifying heritable connective tissue disorders in childhood. The Practitioner 256(1752):19-24.

Beighton P, Solomon L, Soskolne CL. 1973. Articular mobility in an African population. Ann Rheum Dis 32:413-418.

Beighton P, Grahame R, Bird H. Hypermobility of joints. 1999. 3rd ed. London: SpringerVerlag.

Bird HA, Tribe CR, Bacon PA. 1978. Joint hypermobility leading to osteoarthrosis and chondrocalcinosis. Ann Rheum Dis 37:203-211. 
298 299

300

301

302

303

304

305

306

307

308

309

310

311

312

313

314

315

316

317

318

319

320

321

322

323

324

325

326

327 328

Bird HA. 2005. Joint hypermobility in children. Rheumatology 44:703-704.

Bulbena A, Duro JC, Porta M, Faus S, Vallescar R. 1992. Clinical assessment of hypermobility of joints: assembling criteria. J Rheumatol 19:115-122.

Carter C, Wilkinson J. 1964. Persistent joint laxity and congenital dislocation of the hip. J Bone Joint Surg Br 46:40-45.

Clinch J, Deere K, Sayers A, Palmer S, Riddoch C, Tobias JH, Clark EM. 2011. Epidemiology of generalized joint laxity (hypermobility) in fourteen-year-old children from the UK: a population-based evaluation. Arthritis Rheumatism 63:2819-2827.

Corben T, Lewis JS, Petty NJ. 2008. Contribution of lumbar spine and hip movements during the palms to floor test in individuals with diagnosed hypermobility syndrome. Physiother Theory Pract 24:1-12.

El-Garf AK, Mahmoud GA, Mahgoub EH. 1998. Hypermobility among Egyptian children: prevalence and features. J Rheumatol 25:1003-1005.

Gajdosik RL, Albert CR, Mitman JJ. 1994. Influence of hamstring length on the standing position and flexion range of motion of the pelvic angle, lumbar angle and thoracic angle. $J$ Orthop Sports Phys Ther 20:213-219.

Gerver WJM, de Bruin R. 2001. Paediatric morphometrics: A reference manual. 2 ${ }^{\text {nd }}$ ed. Maastricht, Germany: Universitaire Pers Maastricht.

Grahame R. 1999. Joint hypermobility and genetic collagen disorders: are they related? Arch Dis Child 80:188-191.

Grahame R. 2000. Hypermobility—not a circus act. Int J Clin Pract 54:314-315. 
329

330

331

332

333

334

335

336

337

338

339

340

341

342

343

344

345

346

347

348

349

350

351

352

353

354

355

356

357

358

359

Gyldenkerne B, Iversen K, Roegind H, Fastrup D, Hall K, Remvig L. 2007. Prevalence of general hypermobility in 12-13-year-old school children and impact of an intervention against injury and pain incidence. Advan Physiother 9:10-15.

Hasija RP, Khubchandani RP, Shenoi S. 2008. Pediatric rheumatology-joint hypermobility in Indian children. Clin Exp Rheumatol 26:146-150.

Hudson N, Starr MR, Esdaile JM, Fitzcharles MA. 1995. Diagnostic associations with hypermobility in rheumatology patients. Br J Rheumatol 34:1157-1161.

Jaffe M, Tirosh E, Cohen A, Taub Y. 1988. Joint mobility and motor development. Archives of disease in childhood 63(2):159-161.

Jansson A, Saartok T, Werner S, Renström P. 2004. General joint laxity in 1845 Swedish school children of different ages: age- and gender-specific distributions. Acta Pcediatrica 93:1202-1206.

Jessee EF, Owen DS, Jr, Sagar KB. 1980. The benign hypermobile joint syndrome. Arthritis Rheum 23:1053-1056.

Juul-Kristensen B, Schmedling K, Rombaut L, Lund H, Engelbert RHH. 2017. Measurement properties of clinical assessment methods for classifying generalized joint hypermobility- A systematic review. Am J Med Genet Part C Semin Med Genet 175C:116-147.

Juul B, Rogind H, Jensen DV, Remvig L. 2007. Inter-examiner reproducibility of tests and criteria for generalized joint hypermobility and benign joint hypermobility syndrome. Rheumatology 46:1835-1841.

Lamari NM, Chueire AG, Cordeiro JA. 2005. Analysis of joint mobility patterns among preschool children. Sao Paulo Med J 123:119-123. 
360

361

362

363

364

365

366

367

368

369

370

371

372

373

374

375

376

377

378

379

380

381

382

383

384

385

386

387

388
Larsson LG, Baum J, Mudholkar GS. 1987. Hypermobility: features and differential incidence between the sexes. Arthritis Rheum 30:1426-1430.

Leone V, Tornese G, Zerial M, Locatelli C, Ciambra R, Bensa M, Pocecco M. 2009. Joint hypermobility and its relationship to musculoskeletal pain in schoolchildren: a cross-sectional study. Arch Dis Childhood 94:627-632.

Malfait F, Francomano C, Byers P, Belmont J, Berglund B, Black J, Bloom L, Bowen JM, Brady AF, Burrows NP, Castori M, Cohen H, Colombi M, Demirdas S, Backer JD, Paepe AD, Fournel-Gigleux S, Frank M, Ghali N, Giunta C, Grahame R, Hakim A, Jeunemaitre X, Johnson D, Juul-Kristensen B, Kapferer-Seebacher I, Kazkaz H, Kosho T, Lavallee ME, Levy H, Mendoza-Londono R, Pepin M, Pope FM, Reinstein E, Robert L, Rohrbach M, Sanders L, Sobey GJ, Damme TV, Vandersteen A, Mourik CV, Voermans N, Wheeldon N, Zschocke J, Tinkl B. 2017. The 2017 international classification of the Ehlers-Danlos syndromes. Am J Med Genet Part C Semin Med Genet 175C:8-26.

Mikkelsson M, Salminen JJ, Kautiainen H. 1996. Joint hypermobility is not a contributing factor to musculoskeletal pain in pre-adolescents. J Rheumatol 23:1963-1967.

Palmer S, Cramp F, Lewis R, Muhammad S, Clark E. 2015. Diagnosis, management and assessment of adults with joint hypermobility syndrome: A UK-wide survey of physiotherapy practice. Musculoskeletal Care 13(2):101-11.

Palmer S, Bailey S, Barker L, Barney L, Elliott A. 2014. The effectiveness of therapeutic exercise for joint hypermobility syndrome: a systematic review. Physiotherapy 100(3):220-7.

Qvindesland A, Jonsson H. 1999. Articular hypermobility in Icelandic 12-year-olds. Rheumatology 38:1014-1016. 
389 Reuter PR, Fichthorn KR. 2019. Prevalence of generalized joint hypermobility, 390 musculoskeletal injuries, and chronic musculoskeletal pain among American university $391 \quad$ students. PeerJ ; 7:e7625.

392

393 Romeo DM, Lucibello S, Musto E, Brogna C, Ferrantini G, Velli C, Cota F, Ricci D, Mercuri 394 E. 2016. Assessing joint hypermobility in preschool-aged children. J Pediatr 176:162-166.

395

396 Seçkin Ü, Tur BS, Yılmaz Ö, Yağcı İ, Bodur H, Arasıl T. 2005. The prevalence of joint 397 hypermobility among high school students. Rheumatol Intl 25:260-263.

398

Silman AJ, Day SJ, Haskard DO. 1987. Factors associated with joint mobility in an adolescent 400 population. Ann Rheum Dis 46:209-212.

401

402

Sirajudeen MS. 2020. Physical Therapy Management for Child with Generalized Joint 403 Hypermobility. Majmaah Journal of Health Sciences 8(1):113-119.

404

405 Smits-Engelsman B, Klerks M, Kirby A. 2011. Beighton score: a valid measure for generalized 406 hypermobility in children. J Pediatr 158:119-123.

407

408 Vougiouka O, Moustaki M, Tsanaktsi M. 2000. Benign hypermobility syndrome in Greek 409 schoolchildren. Eur J Pediatr. 159:628.

410 
Table $\mathbf{1}$ (on next page)

Personal characteristics of participating children 
1 Table 1 Personal characteristics of participating children

2

\begin{tabular}{|l|c|}
\hline \multicolumn{1}{c|}{ Characteristic } & Frequency (\%)/Mean (SD) \\
\hline Sex & $142(46.9)$ \\
\hline Male & $161(53.1)$ \\
\hline Female & $10.74(1.24)$ \\
\hline Age (years) & $138.10(11.7)$ \\
\hline Height & $37.90(12.1)$ \\
\hline Weight & $161(53.1)$ \\
\hline BMI & $105(34.7)$ \\
\hline Underweight & $24(7.9)$ \\
\hline Normal weight & $13(4.3)$ \\
\hline Overweight & $13(4.3)$ \\
\hline Obese & $290(95.7)$ \\
\hline Hand dominance & \\
\hline Left & \\
\hline Right & \\
\hline
\end{tabular}

Notes:

Abbreviations: $\mathrm{BMI}$, body mass index; SD, standard deviation 


\section{Table 2 (on next page)}

Frequency distribution of total Beighton score and prevalence of generalized joint hypermobility (based on cutoff $\geq 4$ or $\geq 6$ ) 
Table 2 Frequency distribution of total Beighton score and prevalence of generalized joint hypermobility (based on cutoff $\geq 4$ or $\geq 6$ )

\begin{tabular}{|c|c|}
\hline Score & Frequency (\%) \\
\hline $\mathbf{0}$ & $229(75.6)$ \\
\hline 1 & $5(1.7)$ \\
\hline 2 & $22(7.3)$ \\
\hline 3 & $1(0.3)$ \\
\hline 4 & $21(6.9)$ \\
\hline 5 & $2(0.7)$ \\
\hline 6 & $13(4.3)$ \\
\hline 7 & $1(0.3)$ \\
\hline 8 & $9(3)$ \\
\hline 9 & $0(0)$ \\
\hline Hypermobility & $46(15.2)$ \\
\hline Cutoff $\geq 4$ & $23(7.6)$ \\
\hline Cutoff $\geq 6$ &
\end{tabular}




\section{Table $\mathbf{3}$ (on next page)}

Point prevalence of joint hypermobility at various sites used in the Beighton criteria 
2 Table 3 Point prevalence of joint hypermobility at various sites used in the Beighton criteria (Cut-off $\geq 4$ )

\begin{tabular}{|c|c|c|c|c|}
\hline Beighton Site & $\begin{array}{c}\text { All } \\
(n=303) \\
\text { Frequency }(\%)\end{array}$ & $\begin{array}{c}\text { Male } \\
(n=142) \\
\text { Frequency }(\%)\end{array}$ & $\begin{array}{c}\text { Female } \\
(n=161) \\
\text { Frequency }(\%)\end{array}$ & P Value \\
\hline Little Finger & & & & \\
\hline Left & $35(11.5)$ & $22(15.5)$ & $13(8.1)$ & $0.043^{*}$ \\
\hline Right & $38(12.5)$ & $26(18.3)$ & $12(7.4)$ & $0.004^{*}$ \\
\hline Thump & & & & \\
\hline Left & $38(12.5)$ & $7(4.9)$ & $31(19.2)$ & $0.000^{*}$ \\
\hline Right & $36(11.9)$ & $7(4.9)$ & $29(18)$ & $0.002^{*}$ \\
\hline Elbow & & & & \\
\hline Left & $52(17.2)$ & 25 (17.6) & $27(16.8)$ & 0.618 \\
\hline Right & $52(17.2)$ & $25(17.6)$ & $27(16.8)$ & 0.636 \\
\hline Knee & & & & \\
\hline Left & $26(8.6)$ & $9(6.3)$ & $17(10.6)$ & 0.191 \\
\hline Right & $24(7.9)$ & $8(5.6)$ & $16(9.9)$ & 0.166 \\
\hline Trunk & $2(0.7)$ & $0(0)$ & $2(1.2)$ & 0.182 \\
\hline
\end{tabular}




\section{Table 4 (on next page)}

Association between personal characteristics and presence of generalized joint hypermobility (based on Beighton score $\geq 4$, or $\geq 6$ ) 
Table 4 Association between personal characteristics and presence of generalized joint hypermobility (based on Beighton score $\geq 4$, or $\geq 6$ )

\begin{tabular}{|c|c|c|c|c|c|c|}
\hline \multirow[b]{2}{*}{ Characteristics } & \multicolumn{3}{|c|}{ Hypermobility (Beighton score $\geq 4$ ) } & \multicolumn{3}{|c|}{ Hypermobility (Beighton score $\geq 6$ ) } \\
\hline & Yes & No & $\begin{array}{c}\mathbf{P} \\
\text { Value }\end{array}$ & Yes & No & P Value \\
\hline \multicolumn{7}{|l|}{ Total $(N=303)$} \\
\hline \multicolumn{6}{|l|}{ Sex } & \multirow{3}{*}{$0.100^{a}$} \\
\hline Male & 19 & 123 & \multirow[t]{2}{*}{$0.411^{\mathrm{a}}$} & 7 & 135 & \\
\hline Female & 27 & 134 & & 16 & 145 & \\
\hline Age (years) ; Mean (SD) & $\begin{array}{l}10.39 \\
(1.10)\end{array}$ & $10.79(1.25)$ & $0.025^{b^{*}}$ & $10.34(1.33)$ & $10.76(1.22)$ & $0.167^{b}$ \\
\hline BMI; Mean (SD) & $\begin{array}{l}17.87 \\
(3.64) \\
\end{array}$ & $19.71(4.97)$ & $0.029^{b *}$ & $17.64(2.97)$ & 19.58 (4.93) & $0.090^{b}$ \\
\hline \multicolumn{3}{|l|}{ Hand dominance } & \multirow{3}{*}{$0.441^{a}$} & & & \multirow{3}{*}{$0.291^{a}$} \\
\hline Left & 3 & 12 & & 2 & 13 & \\
\hline Right & 43 & 245 & & 21 & 267 & \\
\hline \multicolumn{7}{|l|}{ Males $(N=142)$} \\
\hline Age (years); Mean (SD) & $\begin{array}{l}10.69 \\
(0.83)\end{array}$ & $11.04(1.23)$ & $0.055^{b}$ & $11(0.58)$ & $10.99(1.21)$ & $0.694^{b}$ \\
\hline BMI; Mean (SD) & $\begin{array}{l}18.72 \\
(3.84) \\
\end{array}$ & $19.87(5.46)$ & 0.75 & $18.75(2.91)$ & $19.77(5.37)$ & $0.973^{b}$ \\
\hline \multicolumn{6}{|l|}{ Hand dominance } & \multirow{3}{*}{$0.455^{\mathrm{a}}$} \\
\hline Left & 2 & 9 & $0.745^{a}$ & 1 & 10 & \\
\hline Right & 17 & 114 & & 6 & 125 & \\
\hline \multicolumn{7}{|l|}{ Females ( $N=161)$} \\
\hline Age (years); Mean (SD) & $\begin{array}{l}10.19 \\
(1.25) \\
\end{array}$ & $10.59(1.25)$ & $0.146^{b}$ & $10.07(1.49)$ & $10.57(1.22)$ & $0.163^{b}$ \\
\hline BMI; Mean (SD) & $\begin{array}{l}17.28 \\
(3.44) \\
\end{array}$ & $19.57(4.50)$ & $0.011^{b *}$ & 17.15 (2.95) & $19.41(4.50)$ & $0.041^{\mathrm{b} *}$ \\
\hline \multicolumn{6}{|l|}{ Hand dominance } & \multirow{3}{*}{$0.561^{a}$} \\
\hline Left & 1 & 3 & \multirow{2}{*}{$0.433^{a}$} & 1 & 3 & \\
\hline Right & 26 & 131 & & 15 & 142 & \\
\hline
\end{tabular}

